\title{
Refractory Malignant Neoplasm
}

National Cancer Institute

\section{Source}

National Cancer Institute. Refractory Malignant Neoplasm. NCI Thesaurus. Code C120186.

A malignant neoplasm that does not respond to treatment. 